\title{
O CERRADO E A REESTRUTURAÇÃO DO TERRITÓRIO: O CASO DA MICRORREGIÃO DE RONDONÓPOLIS, MT
}

\author{
SAVANNAH AND TERRITORIAL RESTRUCTURING: THE SITUATION OF \\ RONDONOPOLIS MICROREGION IN MATO GROSSO STATE
}

\author{
LA SAVANE ET DE RESTRUCTURATION DU TERRITOIRE: LE CAS DE LA \\ MICROREGION RONDONOPOLIS, MT
}

Roberto de Souza Santos - Universidade do Tocantins - Porto Nacional - Tocantins - Brasil

robertosantos@uft.edu.br

\begin{abstract}
Resumo
0 presente artigo tem por objetivo identificar como as políticas públicas desenharam a organização territorial da Microrregião de Rondonópolis, MT, no interior da acumulação capitalista, a partir da introdução do progresso técnico-científico na agropecuária, que atingiu a dinâmica socioespacial e natural do geossistema. Faz também uma discussão teórica a respeito de como se estruturou e se espacializou o processo de modernização agropecuária na microrregião.
\end{abstract}

Palavras-chave: modernização-agropecuária, microrregião, cerrado, reestruturação do território.

\begin{abstract}
This article aims to identify how public policies territorially organized Rondonopolis Microregion in Mato Grosso State, within the capitalist accumulation, from the introduction of the technical and scientific progress on farming and cattle raising, which reached the geosystem social-spatial and natural dynamic. It also makes a theoretical discussion on how the farming and cattle raising modernization process was structured and spatially distributed in that region.

Key words: modernization, farming and cattle raising, microregion, savannah, territorial restructuring.
\end{abstract}

\section{Résumé}

Cet article vise à identifier comment les politiques publiques visant l'organisation territoriale de la microrégion Rondonópolis, MT, au sein de l'accumulation capitaliste, de l'introduction de progrès scientifique et technique dans le secteur agricole, qui a atteint la dynamique des géosystèmes naturels et socio. Il fait également une discussion théorique sur la façon structurée et le processus de modernisation de l'agriculture dans le micro.

Mots-clés: la modernisation, l'agriculture, le micro, la savane, la restructuration du territoire.

\section{Introdução}

Este artigo levanta uma discussão teórica no que diz respeito ao cerrado. Destaca os principais componentes naturais que o compõem, procura abordar como o homem ocidental se apropria de forma mercantil do cerrado, através de seus atributos técnicos modernos, e como as políticas públicas desenharam a organização territorial na Microrregião de Rondonópolis, MT, num processo desenvolvido no interior da acumu- 
lação capitalista, por meio da introdução do progresso técnico-científico na agropecuária. O artigo procura também relatar o processo de reestruturação espacial da microrregião, resultado da inserção desse mesmo progresso técnico.

No mapa 1 pode-se localizar a Microrregião de Rondonópolis, MT.

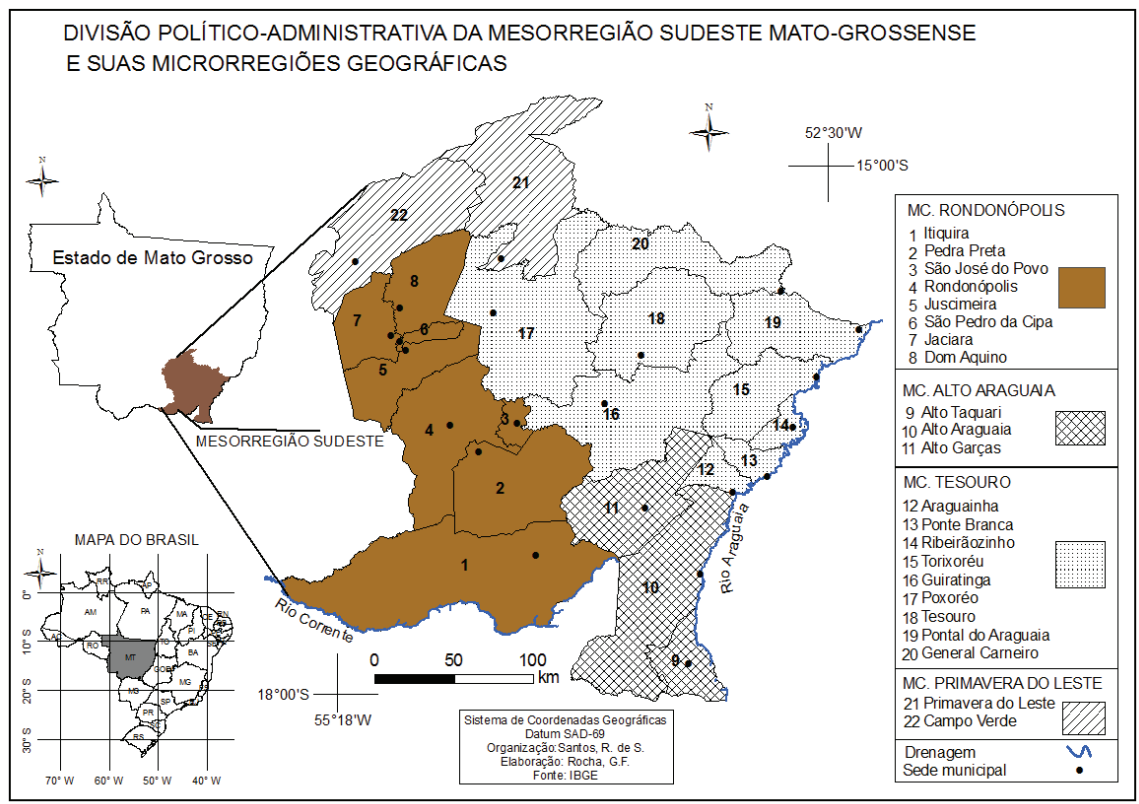

Para caracterizar o processo de apropriação e de ocupação do cerrado do Mato Grosso dividiu-se este processo em quatro fases. A primeira fase se estende até 1870, marcada pela presença geopolítica da Coroa portuguesa no controle militar do território. A segunda vai aproximadamente de 1870 a 1930, caracterizada pela evolução da infraestrutura ferroviária. A terceira inicia-se em 1930, fortemente marcada pela concessão de terras na colonização oficial e pela doação de glebas no interior do estado, quando o poder público passou a dimensionar sua estratégia política de colonização e ocupação do território mato-grossense. A quarta fase e última corresponde ao período a partir de 1970, quando chega ao estado a fronteira agrícola mecanizada voltada para a economia de mercado interno e externo. 
Acredita-se que em cada uma dessas fases, há uma reestruturação do território na tentativa de buscar respostas favoráveis à reprodução do modo de produção capitalista. E a ocupação do território não indica somente a ocupação baseada na incorporação de novas terras ao processo produtivo de caráter econômico ou demográfico, mas também revela a apropriação mercantil do espaço geográfico, onde o território sempre é objeto de ocupação e apropriação pelos atores sociais e pelo poder público.

\section{Componentes naturais do cerrado}

O cerrado é um tipo de vegetação que se caracteriza pela presença de estrato arbóreo e estrato herbáceo. Segundo Christofoletti (1979, p. 4041), para o estrato arbóreo consideram-se as seguintes variáveis: densidade arbustiva (número de árvores/área); intensidade florística (número de espécies/área); distância média entre as árvores; área recoberta pelas copas (por unidade de área padrão); índice de ramificação das espécies; biomassa por área padrão; altura das árvores. Para o estrato herbáceo, pode-se mencionar: altura da cobertura herbácea; área ocupada por esta cobertura; densidade das herbáceas (número de plantas/área); biomassa.

No Brasil, a área de cerrado estende-se por vários estados: Goiás, Tocantins, Mato Grosso do Sul, região sul de Mato Grosso, oeste e norte de Minas Gerais, oeste da Bahia e Distrito Federal, sendo, portanto, um dos maiores ecossistemas do país.

Caracteriza-se também como uma savana com vegetação arbórea bem esparsa, que se distingue de outras comunidades vegetais do Brasil pela sua fisionomia. Sua vegetação é um mosaico de campos limpos, sujos e cerradão, constituídos de árvores de casca grossa, tortuosas, com plantas xeromórficas que lembram as regiões semidesérticas. As plantas estão adaptadas para retirar água profunda através de raízes que atingem até 15 metros.

Os solos da área são de sedimentos que se originam do Terciário, bastante profundos, azonados, de cor vermelha, porosos, permeáveis e bem drenados, portanto muito lixiviados. São geralmente pobres em nutrientes, devido à sua origem associada a depósitos sedimentares antigos, que vêm sofrendo pedogênese há milhares de anos, conforme explicam Conti e Furlan (1995). De acordo com as diferentes condições geomorfológicas, geológicas e climáticas, os solos dos cerrados variam de textura, estrutura, perfil e profundidade. 
Os solos do cerrado brasileiro, além da deficiência em nutrientes, apresentam alta concentração de alumínio, o que determina uma propriedade importante: a capacidade de troca catiônica, fundamental no metabolismo nutricional das plantas. A composição química do solo, porém, é muito ácida, devido exatamente à grande presença de alumínio, que é tóxico para a maioria das espécies utilizadas na agricultura. É necessária, então, a correção de seu pH (potencial hidrogeniônico) por meio da aplicação de calcário, de preferência o calcário dolomítico que é um carbonato de magnésio; é preciso, também, fazer adubação adequada. Dessa forma, os cerrados tornam-se grandes áreas de cultivo agrícola para exportação e consumo interno. A correção do solo para o plantio mecanizado em grande escala é feita pela adubação com fertilizantes industriais com o uso de tecnologias biogenéticas e recebe o apoio das políticas públicas de investimento regional instituídas especificamente para essas áreas.

Quanto ao relevo, compõe-se de grandes chapadões planos com altitudes entre 300 e 600 metros acima do nível do mar, o que facilita o trabalho mecanizado. Além disso, situa-se geograficamente numa área de grande insolação, fator que contribui para certos tipos de plantio agrícola. O sistema de drenagem, por sua vez, sofre grande influência da topografia, caracterizada por rios permanentes ladeados por matas de galeria e buritizais (Conti; Furlan, 1995).

Cerrado: um ecossistema em extinção

O cerrado não constitui apenas um ecossistema composto por vegetais, animais, clima, rede hidrográfica, solo e outros elementos físicos; há também o homem, que se apropria dele e o submete a transformações com o objetivo de buscar uma paisagem cada vez mais cultural e humanizada. Portanto, o conceito de cerrado como um ecossistema formado somente pelos fatores físicos e biológicos, sem incluir o homem, não é mais aceito, a partir do momento em que o cerrado se tornou objeto de apropriação mercantil pela "burguesia do agronegócio".

A produção espaço-temporal do território de Mato Grosso pode ser dividida em quatro fases. A primeira, até 1870, foi marcada pela presença geopolítica da Coroa portuguesa no controle militar do território, principalmente com a criação da primeira capital de Mato Grosso, Vila Bela da Santíssima Trindade, localizada no sudoeste da Província e fundada no dia 29 de janeiro de 1748, ano em que se criou também a Capitania de 
Mato Grosso, desmembrada da Capitania de São Paulo. Tal fase também se caracterizou pelas atividades econômicas que visavam assegurar o controle do território, como, por exemplo, a atividade canavieira, que desde 1727 já teria se estabelecido na região, embora tenha atingido seu desenvolvimento definitivo por volta de 1888, quando se registra o surgimento das primeiras agroindústrias do açúcar. Segundo Borges (1991), as principais propriedades territoriais destinadas a essas atividades foram controladas por companhias estrangeiras, como The Brazilian Meat Company, Fomento Argentino Sud-Americano, Franco-Brasileira, The Miranda Estancia Company, Sud-Américaine Belge S/A, e The Água Limpa Syndicate, com fazendas entre 5.000 e 884.231 hectares. Esses grupos agiram na forma de monopólios e tornaram mais intensos os processos de concentração fundiária. No período, estes atores sociais foram praticamente os donos do poder econômico e político, do processo produtivo e, por que não dizer, do território mato-grossense.

A partir de 1856, com a abertura da navegação pelo rio Paraguai, abriu-se a possibilidade de produzir o açúcar para exportação em Mato Grosso. Aí, formaram-se grandes propriedades, fazendas de cana-de-açúcar, surgindo uma elite com força política suficiente para se impor no cenário regional e se alternar no poder com os representantes de oligarquias do sul, formadas por pecuaristas e representantes da Companhia Erva-Mate Laranjeira.

A erva-mate, planta nativa da América já conhecida pelos índios, que a utilizavam como estimulante dos músculos e sistema nervoso tornou-se relevante atividade produtiva com a abertura da Hidrovia Paraguai, sendo exportada para a Argentina. Com isso, possibilitou a criação da Companhia Erva-Mate Laranjeira, que financiou na época a abertura de estradas, hidrovia e pontes e controlou a embarcação do produto, além de ter fábricas para a sua transformação e ser a grande responsável pela construção da ferrovia Noroeste do Brasil, ligando o Mato Grosso do Sul a São Paulo (Piaia, 1997). A atividade econômica da erva-mate foi a de maior destaque, do ponto de vista do poder político e econômico no passado de Mato Grosso.

A segunda fase vai aproximadamente de 1870 a 1930. A partir de 1870, a evolução da infraestrutura ferroviária condicionou grandes transformações econômicas e espaciais na região sul do estado, que passam a incorporá-la ao dinamismo econômico paulista. Tal incorporação proporcionou a intensificação da atividade econômica extrativa e, em con- 
sequência, Mato Grosso experimentou um outro surto migratório e de povoamento, orientado pela extração da borracha, ipecacuanha (ou poaia, uma planta medicinal), cana-de-açúcar e erva-mate, produtos de grande aceitação no mercado externo (Piaia, 1997, p. 19-20). Como nos últimos anos do século XIX teve início essa nova fase econômica em Mato Grosso - a da exploração vegetal, baseada, inicialmente, na produção da erva-mate e da poaia e, posteriormente, da borracha - alguns atores sociais da atividade extrativa vegetal, de grande demanda na época, lidavam no mercado mundial e passaram a selecionar novas porções do espaço geográfico de Mato Grosso, na busca do domínio de sua territorialidade (Moura, 1983). Além da já existente criação bovina, houve também a industrialização do setor, com a introdução do extrato e caldo de carne e do charque, na década de 1920 (Borges, 1991).

A terceira fase da produção espaço-temporal do território mato-grossense iniciou-se em 1930 e perdurou até 1970, sendo fortemente marcada pela concessão de terras via colonização oficial e doação de glebas no interior do estado. Nos anos 1930, as terras devolutas foram vendidas a empresas colonizadoras, e as áreas de colonização oficial ficaram reservadas a pessoas físicas. O poder público passou a dimensionar sua estratégia política de colonização e ocupação do território mato-grossense com a privatização de suas terras devolutas e a instalação da colonização dirigida (pública). Foi a partir de 1930, no momento do nascimento e solidificação do capital industrial no Brasil, que Mato Grosso passou a viver uma nova fase econômica e, consequentemente, de transformação espacial, com o surgimento da força econômica e política da burguesia industrial brasileira, com grande poder político na organização do território.

Norteado pela política de colonização, o governo estadual, na década de 1940, adotou a mesma estratégia iniciada por parte do governo federal e, em 1947, de modo a acelerar essa política, criaram-se diversos organismos, cuja atribuição principal era a fundação e organização de colônias agrícolas para o domínio do território (Moura, 1983). Entre as décadas de 1940 e 50, foram criadas na região sul do estado, pelo Departamento de Terras e Colonização (DTC, órgão estadual), as colônias agrícolas estaduais e particulares de Mutum (1939), Paraíso (1943), Nossa Senhora de Fátima (1947), Paulista (1948), Coronel Ponce (1948), Alto Coité (1948), Naboreiro (1949), Macacos (1949) e Rondonópolis (1948), conforme relato de Gontijo (1988, p. 48). A ocupação do território se estabeleceu de 
modo mais racional, com ações políticas dirigidas mais racionalmente, por intermédio das políticas públicas da Marcha para o Oeste.

A Marcha para o Oeste designou a política de ocupação territorial instituída com a criação de colônias agrícolas, no primeiro mandato de Vargas, na década de 1940, devido à necessidade urgente de abrir novas fronteiras econômicas e ampliar a malha viária no Centro-Oeste para favorecer a penetração do capital agropecuário na região. Incentivou-se a produção na pequena propriedade, que seria responsável pelo abastecimento de grãos na fronteira em expansão, constituída em sua maioria por nordestinos migrados do Sudeste (Gontijo, 1988, p. 40-45). A Marcha para o Oeste constituiu uma estratégia política da época para a ocupação demográfica e depois econômica do território.

Entre 1950 e 1955, o governo mato-grossense adotou uma política destinada a sistematizar a ocupação das terras e a expansão da fronteira agrícola. De início, o Estado incentivou a implantação de empresas colonizadoras particulares, mas não teve êxito e os colonos ficaram inadimplentes. Posteriormente, as terras foram devolvidas ao Estado, explica Demamann (1997, p. 227). Isso induz a pensar que, quando as coisas não dão certo no capitalismo, o Estado keynesiano abraça a causa para resolvê-la - pelo menos é o que ocorreu neste período de 1930 até os anos noventa.

Outro fator de ocupação foi a descoberta do ouro, que deu origem a muitas povoações, localizadas na porção central de Mato Grosso, com a consequente ocupação das áreas de cerrado onde se encontravam os veios auríferos. Contudo, esse processo acarretou menos destruição do meio ambiente do que a provocada pela ocupação agrícola em andamento.

A partir de 1960, iniciou-se a abertura de rodovias e a construção de Brasília, com o objetivo de consolidar a ocupação demográfica, econômica e geopolítica das regiões vazias do Centro-Oeste. Nos vários ciclos desse processo histórico, por meio de ocupações humanas, o cerrado foi aos poucos se transformando de um ecossistema natural em paisagens culturais, com repercussões no meio ambiente.

Os colonos eram em sua maioria pequenos proprietários, o que permitia a eles, como atores sociais, buscarem sua própria territorialidade. Mas não era nada fácil, pois os atores econômicos donos dos meios de produção a bloqueavam. A título de exemplo, pode-se observar, atualmente, o mecanismo de tirar o emprego do trabalhador por meio da máquina (da robótica), o que confere amplos poderes aos proprietários dos meios de 
produção. Em nossos dias, as relações de produção apresentam-se mais assimétricas e mais exploradoras do que as de antes.

Finalmente, a quarta fase corresponde ao período a partir de 1970, quando chegaram a Rondonópolis vários imigrantes sulistas à procura de terras mais baratas, como as do cerrado, que na época eram comercializadas a preços baixíssimos, o que lhes permitiu adquirir grandes áreas de terra por um pequeno custo. Isto significa que a venda de suas terras no sul, por menor que fosse o preço, daria para comprar imensos imóveis nas áreas de cerrado, contando ainda com o apoio financeiro do poder público, por meio das políticas públicas de investimento do Planalto Central.

Nos dias atuais, como a ocupação do espaço local é explicitamente econômica, é denominada, na presente discussão teórica, "ocupação econômica do território”. A ocupação econômica do território é objeto de um poder central comandado pelos atores econômicos que, ao mesmo tempo, controlam todo o processo produtivo regional, impondo sua racionalidade de crescimento econômico. Todavia, convém lembrar que, durante muito tempo, os cerrados foram considerados "improdutivos". Ademais, as atividades de extração vegetal e mineral, antes dos anos 1970, mesmo no cerrado ou nas áreas de "terras de cultura”, não causavam muita agressão à natureza. Atualmente, pelo contrário, há estimativas de que restam apenas $20 \%$ do ecossistema do cerrado.

Na Microrregião de Rondonópolis, MT, a reestruturação do território implicou uma profunda alteração no processo produtivo, com as fortes mudanças que foram introduzidas nas relações sociais de produção e com as respostas verificadas no geossistema. A partir do momento em que o homem "pós-moderno" se inseriu no cerrado, por intermédio de seus instrumentos técnicos, pode-se afirmar que esta área passou a ser um "espaço instrumentalizado", tornando-se a grande responsável pela produção de grãos no cenário nacional. A conquista do cerrado foi a grande invenção dos trópicos no século XX.

\section{Formação do espaço geográfico}

Quanto à formação do espaço geográfico do ponto de vista da produção espaço-temporal, especificamente na Microrregião de Rondonópolis, Monteiro (2004) considera que a análise desse processo permite estabelecer três períodos. O primeiro período de colonização vai de 1902 
à década de 1940; corresponde ao período inicial, quando no antigo território havia a etnia Bororo. Em agosto de 1915, foi promulgado o Decreto-Lei n. 395, pelo Presidente do Estado, determinando a doação de 2.000 ha destinados à formação do patrimônio de Rio Vermelho, denominação que perdurou até 1919, quando, em homenagem ao Marechal Rondon, passou a denominar-se Rondonópolis. Mas o povoamento de fato teve início a partir de 1940, quando, com as políticas da Marcha para o Oeste, começou a expansão da fronteira agrícola.

O segundo período de colonização corresponde à implantação das colônias, entre 1947 e os anos 60, coincidindo com a chegada dos pecuaristas. Foi uma época em que o poder público doou terras para colonos por intermédio da colonização pública e privada. As cidades de Jaciara, Rondonópolis e Poxoréo foram criadas a partir desta colonização. Em 1947 se deu a construção da rodovia Cuiabá - Campo Grande, que permitiu o acesso de novos migrantes, facilitando a aquisição de terras na região. Entre 1950 e 60, chegaram pecuaristas mineiros e paulistas, que adquiriram grandes fazendas e ampliaram o processo de pecuarização. A proporção entre o preço da terra em São Paulo e em Rondonópolis era, na época, o equivalente a 7 a 8 por 1 , ou seja, cada alqueire na região do Vale do Paraíba correspondia a 7 ou 8 em Rondonópolis, isso nas zonas de "terras de cultura”; no caso das áreas do cerrado, o preço era consideravelmente menor na época. O sistema de arrendamento foi um regime de exploração agrícola muito utilizado nesta fase.

O terceiro período foi marcado pela passagem da agricultura tradicional para uma agricultura e uma pecuária profissionalizada e mecanizada. Na década de 1970 ocorre a chegada de um novo ator, que mudaria totalmente a concepção da produção agropecuária, com um novo perfil de produtor, por meio de novas tecnologias e gerenciamento, culminando em mudanças na organização do território.

Ainda se pode analisar a produção espaço-temporal da região por meio da fronteira, sabendo que ela organiza e estrutura o território no espaço-tempo. De acordo com Diniz (2003), a fronteira pioneira representa os assentamentos iniciais caracterizados pela ausência de mercados de terra e de trabalho, por rápido crescimento populacional via imigração e por grande disponibilidade de terra.

Há também o caso das fronteiras urbanizadas, que fazem parte de uma herança dos embrionários núcleos urbanos criados no coração dos 
projetos de colonização, muito frequentes na região amazônica. Seu crescimento é condicionado pelo processo de evolução das áreas de assentamento circunvizinhas, tornando-se, portanto, entidades inseparáveis dos projetos agrícolas dos quais se originaram. Os núcleos urbanos de Pedra Preta, Juscimeira, Jaciara e São Pedro da Cipa fazem parte destes projetos na Microrregião de Rondonópolis. As transformações estruturais no seu entorno intensificam os movimentos entre a área rural os núcleos-urbanos, aumentando o tamanho e a complexidade dos núcleos. Eles podem crescer o suficiente nessa complexidade e na organização a ponto de se tornarem novos municípios. ${ }^{1}$ Constituem centros de concentração e redistribuição de mão de obra, formada por ex-colonos e migrantes que não conseguiram acesso à terra. À medida que os centros ganham dinamismo, eles tendem a receber também migrantes oriundos de áreas urbanas, atraídos pelo crescente setor terciário, como é o caso da cidade de Rondonópolis. Nessas áreas, o desejo de adquirir terra ainda é um importante estímulo à imigração.

$\mathrm{Na}$ microrregião, a fronteira agrícola mecanizada encontra-se, teoricamente, em um estágio de mecanização avançado, no qual os núcleos urbanos se estruturaram a partir dos projetos de colonização. Em outras palavras, o processo de reestruturação territorial da Microrregião de Rondonópolis caracteriza-se atualmente por uma "fronteira urbanizada". Por outro lado, pode-se dizer que, até 1970, a ocupação do território em termos locais era uma questão de segurança nacional, geopolítica e demográfica, mas a ocupação econômica e a efetiva integração econômica de Mato Grosso no cenário internacional se verificaram depois de 1970.

A fronteira urbanizada fez da cidade de Rondonópolis uma cidade-região na Mesorregião Sudeste Mato-grossense. Segundo Rosso (1999), a influência da cidade de Rondonópolis na malha urbana na mesorregião é fato cristalizado, pois aí se concentra grande parcela das atividades comerciais, econômicas e de prestação de serviços circunscritas no espaço desta, principalmente aquelas revestidas de um elevado conteúdo técnico. Em nossos dias, a Microrregião de Rondonópolis constitui uma região polarizada dentro do sudeste mato-grossense e, ao mesmo tempo, estabelece uma área de influência em seu entorno imediato. Tal fato a caracteriza como uma cidade-região e a torna um centro que coordena e dirige as atividades de produção, conquistando uma série de funções em relação às demais cidades da microrregião. É importante ressaltar que essa pujança 
da cidade de Rondonópolis é um desdobramento do processo de modernização agropecuária.

A partir deste raciocínio, pode-se responder aos questionamentos: Como era o ecossistema cerrado antes do processo de modernização da economia na Microrregião de Rondonópolis? Ele era constituído pela presença de grandes áreas naturais pouco devastadas, e a ocupação humana dava-se, principalmente, nas áreas de extração mineral. Por que antes da introdução do projeto de modernização técnica e científica no cerrado nenhum ator econômico se interessava pelo solo do cerrado? Isto se deve ao fato de que os solos do cerrado eram considerados "improdutivos" e, para torná-los "produtivos", é necessária correção artificial industrializada, difícil de se conseguir antes de 1970. Também ocorria que, antes desse período, não existia uma preocupação política explícita de ocupar economicamente o cerrado. Os meios de produção utilizados nas áreas de "terras de cultura" ou nas áreas de cerrado proporcionaram menos implicações geoambientais do que os atuais? Sim, visto que a antiga exploração da terra baseava-se em instrumentos rudimentares, de baixo poder destrutivo do ecossistema, como, por exemplo, a roça de toco, em que se utilizava a enxada. Por outro lado, cabe admitir que o desmatamento com uso de machados e motosserra é muito lento, enquanto o desmatamento efetuado atualmente por tratores ${ }^{2}$ detona dezenas de hectares em poucas horas. No solo não eram colocadas quaisquer substâncias químicas, e não havia a adoção intensiva de defensivos agrícolas nem de herbicidas, que são prejudiciais ao ecossistema. Por último, cabe perguntar: Racionalmente, a ação social dos atores da antiga economia microrregional tinha os mesmos ingredientes político-econômicos dos atores sociais da atualidade? Nos dias atuais, os atores econômicos acionam o seu território de modo mais racional, são mais articulados politicamente e dispõem de uma ação social eficaz, condicionada pelo conhecimento técnico-científico e com objetivos definidos, segundo análise de Weber (2002). Além do mais, atualmente, é por intermédio deste conhecimento que se criam as condições ideais para a busca da mais-valia.

\section{Disputa do território no cerrado}

Segundo Silva (2009), os ecossistemas de chapada representam 80,4\% da área do cerrado contínuo, região considerada a recarga hídrica 
do bioma. A localização central do domínio do Cerrado e as características dessas extensas chapadas planas, de solos profundos, geologicamente velhos e permeáveis, fazem dessa região a verdadeira caixa d'água do território brasileiro. Nessa unidade da paisagem é que se dá a disputa entre o agronegócio e o agroextrativismo camponês, pelo modelo de ocupação, produção e desenvolvimento no âmbito do domínio do cerrado. O território das comunidades camponesas é encurralado e rodeado pelo agronegócio.

As comunidades camponesas lutam pela terra e a água em função do processo de desterritorialização no cerrado. A apropriação do cerrado pelas corporações constrange a liberdade das comunidades tradicionais e o território do campesinato; em outras palavras, gera o processo de desterritorialização. Esse processo coloca em risco e constrange o direito de ir, vir e de usar o território (como afirma o geógrafo Milton Santos) das comunidades e do homem trabalhador do campo. As estratégias de apropriação territorial usadas pelas empresas do agronegócio se desenvolvem no sentido de convencer o povo do lugar a aceitar suas propostas de desenvolvimento. Mas infelizmente são poucas as pessoas que reagem e que estão mobilizadas para o confronto territorial.

Há uma contradição entre os interesses "dos de fora" e os "do lugar". Há também contradição entre os que estão de passagem e os que vão ficar no lugar. O impacto que a chegada "dos de fora" e das monoculturas exerce nas comunidades locais espalhadas pelo cerrado é algo real. Isto é, o capital chega e se territorializa enquanto houver recursos naturais para ser explorados. Mas quando as fontes que oxigenam a mais-valia desaparecem, o capital migra para outras fronteiras.

As corporações transnacionais, como a Bunge, Cargill e Multigrain, controlam o processo de territorialização no cerrado, financiando os plantios para garantir o seu abastecimento. A partir desse processo de territorialização do capital, o fracasso das roças de toco e a falência econômica do campesinato atingem sua autoestima, já fragilizada pelo preconceito expresso pelos “de fora”. Essas empresas já estão presentes na Microrregião de Rondonópolis.

A desigualdade de força existente nos embates enfrentados pelo campesinato tradicional, no Brasil em todas as sociedades capitalistas, leva à expropriação, desterritorialização, perda das condições materiais de subsistência e da identidade. O poder público desencadeia um pro- 
cesso de concentração legalizada de terras e de legitimação da ocupação das chapadas altas e planaltos pelas monoculturas. Para Silva (2009), o próprio Estado dá vistoria e título a esses grupos, como se nas áreas de cerrado não existisse ninguém; além disso coloca toda infraestrutura à sua disposição: a pesquisa, a Embrapa e a isenção de impostos para exportação da soja.

Por outro lado, a força de resistência do campesinato não pode ser subestimada. Ela está patente na sua permanência em confronto, no desenvolvimento de novas estratégias de ação, na sua articulação e nas lutas sociais. A resistência está presente para dar suporte à utopia camponesa.

\section{Reestruturação do território}

Convém frisar que a palavra "reestruturação" evoca uma combinação sequencial de sentidos associados a desmoronamento e reconstrução, a desconstrução e tentativa de reconstituição, proveniente de algumas deficiências ou perturbações nos sistemas de pensamento e de ação aceitos, tanto no tempo como no espaço. Os processos de reestruturação social e econômica, no entanto, continuam a ser enterrados sob esquemas evolucionistas idealizados, em que a mudança simplesmente parece acontecer, ou surgir, concretizando alguma marcha inelutável para o "progresso". Tal idealismo evolucionista disfarça o arraigamento da reestruturação na crise e no conflito competitivo entre o velho e o novo, entre a ordem herdada e uma ordem projetada, sendo tal reestruturação desencadeadora de uma intensificação de lutas competitivas pelo controle das forças que configuram a vida material (Soja, 1983). Por outro lado, os períodos de crise são também de dramática reestruturação. O capitalismo está sempre transformando o espaço à sua própria imagem, mas em períodos de expansão isso significa a substituição de padrões mais ou menos estabelecidos num período anterior (Smith, 1988).

Isso implica dizer que a reestruturação do território seria uma das formas de buscar respostas favoráveis à reprodução do modo de produção. Nestes termos, a reestruturação traduz-se num projeto resultante de uma escolha determinada e racionalizada, de compreender, organizar e transformar a realidade no território, num processo em que a escolha inicial define o âmbito das possibilidades, para evitar possibilidades alternativas que são incompatíveis com ela (Marcuse, 1973). 
Analisando a Microrregião de Rondonópolis-MT, percebe-se que a reestruturação do seu território constituiu um projeto arquitetado pelos seguintes atores: poder público e "burguesia do agronegócio", por intermédio da ciência, da técnica e das políticas públicas de investimento, o que equivale a dizer que as políticas públicas atenderam à necessidade da reprodução ampliada do capital industrial, por meio de incentivos fiscais e financiamentos.

\section{Considerações finais}

Diante da discussão teórica exposta acima, entende-se que a reestruturação espacial da microrregião em tempos de globalização parte de um projeto político, talvez não efetivado por uma política explícita, mas por políticas públicas implícitas, em que o fator político fala mais alto do que o econômico. A este respeito, afirma Boyer (1999, p. 13) que "la globalization porte surtout sur la finance et constitue plus l'expression d'un projet politique que d'un déterminisme économique."

Este artigo procurou desenhar teoricamente o processo de reestruturação espacial da Microrregião de Rondonópolis e os motivos que levaram os atores sociais (o poder público e a "burguesia do agronegócio") a fomentar esse projeto de modernização. Identificou a relação do projeto de modernização agropecuária com o meio ambiente, e quais os instrumentos que os atores sociais adotaram para chegar ao processo de territorialização de seus empreendimentos na economia do agronegócio. Constatou, também, que o processo de modernização parte de um projeto filosófico de conteúdo positivista, que em suas etapas sucessivas adquire um conteúdo científico, técnico-científico e, depois, quando manipulado por um agente social, adquire um conteúdo político-ideológico. Nesse processo, o poder econômico, político-ideológico e simbólico entram como variáveis condicionantes do processo de modernização no território.

\section{Notas}

1. Como é o caso de São José do Povo na Microrregião de Rondonópolis, emancipado no início dos anos 1990.

2. No Centro-Oeste, nas áreas de cerrado, utiliza-se intensamente o trabalho mecanizado, por meio de tratores, para o desmatamento. Às vezes, utilizam-se dois tratores, com uma corrente bastante resistente. Os tratores ficam lado a lado, tendo entre eles uma faixa de vegetação, que pode ter vários metros de 
largura; quando os tratores se deslocam, a corrente vai sendo arrastada, arrancando todas as árvores que encontrar pela frente.

\section{Referências}

ARON, Raymond. As etapas do pensamento sociológico. São Paulo: Martins Fontes, 2000.

BECKER, Bertha K. et al. Fronteira amazônica: questões sobre a gestão do território. Brasília: Ed. UnB, 1990.

BECKER, Bertha K. O uso político do território: questões a partir de uma visão do Terceiro Mundo. In: BECKER, Bertha K. et al. (Orgs.). Abordagens políticas da espacialidade. Rio de Janeiro: Ed. UFRJ, 1983.

BORGES, Fernando Tadeu de Miranda. Do extrativismo à pecuária: algumas observações sobre a história econômica de Mato Grosso (1870 a 1930). Cuiabá: Universidade Federal de Mato Grosso, 1991.

BOYER, Robert. La politique à l'ére de la mondialisation et de la finance: le point sur quelques recherches régulationistes. In: BOYER, Robert. L'année de la régulation: économie, institutions, pouvoirs. État et politique économique. V. 3. Paris: La Découverte, 1999.

CALIXTO, Maria José Martinelli Silva. As articulações político-ideológicas do poder público no processo de (re)definição da diferenciação sócio-espacial. Boletim Paulista de Geografia. São Paulo: AGB, n. 78, p. 77-96, dez., 2001.

CARDOSO, Miriam Limoeiro. Ideologia do desenvolvimento - Brasil: JK-JQ. 2. ed. Rio de Janeiro: Paz e Terra, 1978.

CASTRO, Iná Elias. Imaginário político e território: natureza, regionalismo e representação. In: CORREIA, Roberto Lobato et al. (Orgs.). Explorações geográficas: percursos no fim do século. Rio de Janeiro: Bertrand Brasil, 1997.

CHRISTOFOLETTI, Antônio. Análise de sistemas em Geografia. São Paulo: Hucitec, 1979.

CONTI, José Bueno; FURLAN, Sueli Ângelo. Geoecologia: o clima, os solos e a biota. In: ROSS, Jurandy L. Sanches (Org.). Geografia do Brasil. São Paulo: Edusp, 1995.

DEMAMANN, Mírian Terezinha Mundt. O avanço da fronteira agrícola e a redivisão territorial do sudeste mato-grossense. Coletânea n. 2. Instituto de Ciências Humanas e Sociais da UFMT- Campus Universitário de Rondonópolis, MT, 1997.

DINIZ, Alexandre M. A. Migração na fronteira agrícola. In: AGETEO, v. 28, n. 3, set./dez., 2003.

GOETTERT, Jones Dari. O Vôo das Pandorgas: migração sulista para Rondonópolis, MT. Dissertação (Mestrado) - UNESP, Presidente Prudente, SP, 2000. 410 p.

GONTIJO, Nicosina Maria Campos. O brilho e a miséria: a exploração de diamantes em Poxoréo, MT (1930-1940). Brasília: Ed. UnB, 1988, p. 40-45. 
HARVEY, David. Condição pós-moderna. São Paulo: Loyola, 1992.

MARCUSE, Herbert. A ideologia da sociedade industrial. Rio de Janeiro: Jorge Zahar, 1973.

MARTINS, Eduardo de Souza; ALHO, Cléber J. R. (Ed.). De grão em grão, o cerrado perde espaço (cerrado - impactos do processo de ocupação). Brasília, DF: Fundo Mundial para a Natureza, 1995.

MARTINS, José de Souza. Fronteira: a degradação do outro nos confins do humano. São Paulo: Hucitec, 1997.

MONTEIRO, Jorge Luiz Gomes. Mudanças espaciais induzidas pelo progresso técnico: a realidade da agricultura mato-grossense. Tese (Doutorado) - Instituto de Geociências da Universidade Federal do Rio de Janeiro, Rio de Janeiro, 2004. $329 \mathrm{p}$.

MOURA, Sandra Correia. Aspectos da pequena produção em Mato Grosso: o caso de Jaciara e Juscimeira. Dissertação (Mestrado) - Instituto de Geociências, Universidade Federal de Rio de Janeiro, Rio de Janeiro, 1983.

OLIVEIRA, Ariovaldo Umbelino. Integrar para não entregar: políticas públicas e Amazônia. Campinas: Papirus, 1991.

OLIVEIRA, Francisco de. Elegia para uma re(li)gião: nordeste, planejamento e conflitos de classe. Rio de Janeiro: Paz e Terra, 1977.

PIAIA, Ivone Inez. Geografia de Mato Grosso. Cuiabá, MT: Edunic, 1997.

ROSSO, Gilberto Silva de. Influência da cidade de Rondonópolis na rede urbana da Mesorregião Sudeste Mato-grossense. Dissertação (Mestrado) - Faculdade de Ciências e Tecnologia da Unesp, Presidente Prudente, SP, 1999.

SMITH, Neil. Desenvolvimento desigual. São Paulo: Bertrand Brasil, 1988.

SILVA, Carlos Eduardo Mazzetto. O cerrado em disputa: apropriação global e resistências locais. Brasília: Confea, 2009.

SOJA, Edward W. Uma concepção materialista da espacialidade. In: BECKER, Bertha K. et al. (Orgs.). Abordagens políticas da espacialidade. Rio de Janeiro: Ed. UFRJ, 1983.

WEBER, Max. Ciências e política: duas vocações. Tradução de Jean Melvillie. São Paulo: Martin Claret, 2002.

Roberto de Souza Santos - Possui graduação em Geografia pela Universidade Federal de Mato Grosso, mestrado em Planejamento Urbano pela Universidade de Brasília e doutorado em Geografia pelo Instituto de Biociências da Universidade Estadual Paulista. É Pós-doutorando pelo Programa de Pós-graduação do curso de Geografia da Universidade Federal de Goiás e professor da Universidade Federal do Tocantins. 